\title{
Knowledge Mapping of Virtual Academic Communities: A Bibliometric Study Using Visual Analysis
}

\author{
Chunlai Yan ${ }^{1}$, Hongxia $\mathrm{Li}^{*}, 1,2$ \\ ${ }^{1}$ Rattanakosin International College of Creative Entrepreneurship, Rajamangala University of Technology Rattanakosin, \\ Phutthamonthon, 73170, Thailand
}

${ }^{2}$ School of management Science and Engineering, Chongqing Technology and Business University, Chongqing, 400067, China

\begin{tabular}{l} 
A R T I C L E I N F O \\
\hline Article history: \\
Received: 26 May, 2020 \\
Accepted: 14 August, 2020 \\
Online: 24 September, 2020 \\
\hline Keywords: \\
Virtual academic communities \\
Bibliometric \\
Knowledge map \\
Document co-citation analysis \\
Burst detection \\
\end{tabular}

A B S T R A C T
This study aims to provide a systematic and complete knowledge map for researchers in the
field of virtual academic communities (VACs) and to help them quickly understand the key
knowledge, evolution trends and research frontiers. This paper adopts the bibliometric
method, with the help of bibliometric analysis software Citespace and VOSviewer
quantitative analyze the retrieved literature data, and the analysis results are presented in
the form of tables and visualization maps. Analysis of 372 literature data related to VACs
from the Web of Science database shows that: the development of research in this field has
gone through three stages and produced a number of representative key scholars and highly
cited literature; the document co-citation knowledge map and keyword clustering map show
the research hotspots in VACs; the results of burst detection and disciplinary overlay
analysis reveal the research frontier, development trend and disciplinary coverage in
VACs.

\section{Introduction}

The development of internet technology has made significant changes in the way people exchange information. The U.S. Statista survey data shows the rapid growth in global social network users in 2010-2015, with 2.72 billion users expected by 2021 [1]. Facebook, WeChat, Instagram, and other social networks have more than 100 million active users. With the development of new knowledge communication carriers, the mode of academic exchange has also changed, and more scientific research scholars share their knowledge and collaborate in scientific research through online academic exchange platforms. The advancement of Web2.0 technology makes it possible for researchers from different nations to work together with the support of online collaborative platforms, such as virtual academic communities (VACs) [2]. With the coming era of big science and the globalization of science and technology, the internet has gradually become a vital platform for people to participate in social activities and promote intellectual changes in the way of scholar interaction. VACs such as ResearchGate, Academic.edu, Mendeley, and muchong.com have gradually become the sites for researchers to exchange knowledge and share information. The collaboration of researchers based on the VACs has also increased day by day. The

\footnotetext{
* Corresponding author: Hongxia LI, No. 19, Xuefu Ave, Nanan District, Chongqing, P.R.China 400067 +8602362769587, lihongxia@ctbu.edu.cn www.astesj.com
}

VACs are online learning communities for users to exchange academic-related views and resources, and it break through the traditional style of interpersonal communication and improve the efficiency of interaction so that knowledge exchange is not limited by time, space and location [3]. The rise of virtual academic communities has prompted a large number of researchers to become interested in the topic, but it is not easy for researchers to obtain a panoramic view of the knowledge structure, evolution and key nodes in the field. Before the advent of bibliometric tools, researchers mainly rely on peer-reviewed articles or collections of essays to obtain a panoramic view of a discipline or research field. This method lacks of objectivity because of the research peers' knowledge vision and subjective judgment, and often does not reveal the key literature and emerging research hotspots in this field completely and comprehensively, and is easily controversial. The emergence of bibliometric analysis tools provides another possibility for researchers, that is, from simple subjective judgment to subjective judgment combined with objective measurement. This study is guided by this idea.

Bibliometric method is a quantitative analysis method, which takes scientific and technological literature as the research object, and uses mathematical and statistical methods to describe, evaluate and predict the current situation and development trend of each research field. This paper uses two common bibliometric analysis 
software, Citespace and VOSviewer, to study the critical path of knowledge evolution in the field of VACs, to reveal the important knowledge inflection point in this field, and to analyze the potential dynamic mechanism of evolution and the frontier of exploration development through the drawing of a series of visual maps.

\section{Data Source and Research Method}

\subsection{Data source}

Web of Science (WOS) is used as a data source in this paper. WOS contains the Science Citation Index (SCI), the Social Sciences Citation Index (SSCI), the Art \&Humanities Citation Index (A\&HCI), and the CPCI-SSH, which is the deepest and most complete database of citation index data available worldwide. Compared with other large databases such as EBSCO, Springer, Wiley-Blackwell, WOS database covers all SSCI source journals, and its sub-database has high authority in academia [4].This paper retrieves the Web of Science by the search formula (TS=("virtual communit*") OR(TS= "online communit*") OR (TS= "academic blog") OR (TS="question and answer network") OR (TS="social networking sites")) and then filtered the proposed topic by the keyword "academic" and sift through the duplicate literature. Finally, 372 papers are sorted out for this proposed research, which are highly related to the topic of VACs.

\subsection{Research Methodology}

VOSviewer is a JAVA based knowledge mapping software developed by the center for science and technology research at Leiden university in the Netherlands. It presents the structure, evolution, cooperation and other relationships of the knowledge field for literature data [5]. By using VOSviewer, this paper makes statistical analysis of the age and key words of the literature related to the VACs, and combines the synonymous key words to count the high frequency key words. CiteSpace V knowledge visualization software is a multi-dimensional, temporal and dynamic knowledge plotting tool developed by Professor Chen (2006) of Drexel University, USA [6]. The software can convert abstract data into graphic expression (Chen \& Liu, 2005), so that the users can visually see relevant information in the corresponding research field and grasp structural relationship, evolution law and other features of knowledge in the research field by analyzing and understanding the graphs [7]. CiteSpace version 5 is used to analyze the selected literatures in this paper. Firstly, we use the co-citation analysis to sort out the key node literature, and use the clustering and burst detection to analyze the research hotspots and frontier of the VACs; Secondly, we draw the knowledge map to analyze the evolution trend of the research in the field of VACs. Finally, we use the coupling relationship of the literature to analyze the internal relationship between the disciplines involved in the literature.

\section{Data Analysis}

\subsection{General Analysis of Literature}

The annual number of publications in a VACs research area shows the importance of the research results in the VACs field, and the changing trend can measure the overall development of the research field. Table 1 shows the annual number of publications in the VACs field. It can be observed from Table 1 that the annual number of publications in VACs field shows a rising trend, and the whole process gone through three stages: initial development (1995-2007), climbing period (2008-2014), and rapid development period (2015-2020). The number of publications in the period of rapid development shows "well blowout" growth. The above analysis shows that the focus on the VACs is increasing gradually, and with the rapid development of internet technology, this focus is becoming more and more intense.

Table 1: The annual number of publications related to VACs

\begin{tabular}{|l|l|l|l|}
\hline Year & $\begin{array}{l}\text { Amount of } \\
\text { publications }\end{array}$ & Year & $\begin{array}{l}\text { Amount of } \\
\text { publications }\end{array}$ \\
\hline 1995 & 2 & 2008 & 12 \\
\hline 1996 & 0 & 2009 & 17 \\
\hline 1997 & 3 & 2010 & 20 \\
\hline 1998 & 2 & 2011 & 24 \\
\hline 1999 & 1 & 2012 & 20 \\
\hline 2000 & 0 & 2013 & 26 \\
\hline 2001 & 1 & 2014 & 26 \\
\hline 2002 & 1 & 2015 & 42 \\
\hline 2003 & 0 & 2016 & 40 \\
\hline 2004 & 2 & 2017 & 39 \\
\hline 2005 & 7 & 2018 & 38 \\
\hline 2006 & 6 & 2019 & 30 \\
\hline 2007 & 8 & 2020 & 5 \\
\hline
\end{tabular}

\subsection{Research hotspot analysis}

The keywords are brief summaries of the topics and contents of the literature research. It is helpful to know the essential research contents of the literature via correct analysis of the keywords and capable of knowing the hot topics of the subjects, institutions, and research knowledge in a certain period by measuring the number of the keywords [8]. Based on the software called "Citespace V" and the keywords of the publishing, the research on the VACs is visualized. This paper selects the period of 1995-2020 with a time slice of 3 years and the top 50 frequent keywords in each stage for visualization, adopts the Minimum Spanning Tree (MST) to adjustment the graph, and finally the clusters results and extracts them with $\mathrm{k}$ (keyword) as the label to obtain Figure 1.Table 2 is the specific clustering information obtained using the "Cluster Export" function and Table 3 is the high-frequency keyword statistics of the VACs.

The node in the cluster map is the keywords, and its circle area represents the frequency of its appearance. The connection between node and node represents the co-occurrence relationship between keywords, and its thickness indicates the co-occurrence intensity. The structure of Citespace clustering are mainly determined by two indicators: modularity (Q-value for short) and average silhouette (S-value for short). The larger the Q-value, the

better the clustering of the network; moreover, the Q-value interval is $[0,1]$; $\mathrm{Q}>0.3$ indicates the clustering network structure 
is significant. The $\mathrm{S}$-value can be used to measure the homogeneity of the clustering graph; when it is approaching to 1, the homogeneity is higher; when it is above 0.5 , it is considered that the clustering result is reliable. As $\mathrm{Q}=0.5761$ and $\mathrm{S}=0.685$ in Figure 1, it shows that the clustering structure obtained in this study is reliable.

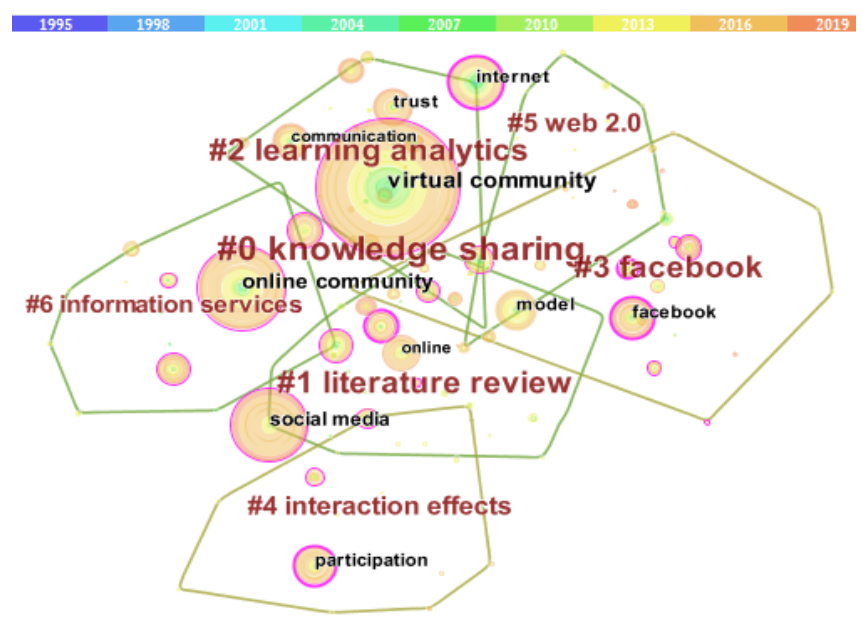

Figure 1: Keyword Clustering Graph of VACs

Table 2: Keyword clustering information of VACs

\begin{tabular}{|l|l|l|l|l|}
\hline $\begin{array}{l}\text { Cluster } \\
\text { ID }\end{array}$ & Term & Size & Silhouette & $\begin{array}{l}\text { Mean } \\
\text { year }\end{array}$ \\
\hline 0 & Knowledge sharing & 22 & 0.757 & 2010 \\
\hline 1 & Literature review & 19 & 0.717 & 2012 \\
\hline 2 & Learning analytics & 19 & 0.645 & 2012 \\
\hline 3 & Facebook & 18 & 0.673 & 2014 \\
\hline 4 & Interaction effects & 14 & 0.841 & 2013 \\
\hline 5 & Web 2.0 & 14 & 0.78 & 2012 \\
\hline 6 & Information services & 12 & 0.887 & 2011 \\
\hline
\end{tabular}

Table 3: High-frequency keywords for VACs ,1995-2020

\begin{tabular}{|l|l|l|l|}
\hline S/N & Keyword & Freq & Centrality \\
\hline 1 & Virtual community & 87 & 0.17 \\
\hline 2 & Online community & 53 & 0.18 \\
\hline 3 & Social media & 46 & 0.12 \\
\hline 4 & Internet & 32 & 0.2 \\
\hline 5 & Model & 26 & 0.03 \\
\hline 6 & Facebook & 25 & 0.22 \\
\hline 7 & Participation & 24 & 0.22 \\
\hline 8 & Trust & 24 & 0.05 \\
\hline 9 & Communication & 23 & 0.07 \\
\hline 10 & Online & 23 & 0.05 \\
\hline 11 & Technology & 21 & 0.19 \\
\hline 12 & Community & 20 & 0.1 \\
\hline 13 & Behavior & 19 & 0.16 \\
\hline 14 & Knowledge & 18 & 0.25 \\
\hline 15 & Education & 17 & 0.14 \\
\hline 16 & word of mouth & 16 & 0.04 \\
\hline 17 & engagement & 15 & 0.19 \\
\hline 18 & network & 14 & 0.06 \\
\hline 19 & impact & 13 & 0.06 \\
\hline 20 & information & 13 & 0.03 \\
\hline
\end{tabular}

\begin{tabular}{|l|l|l|l|}
\hline 21 & motivation & 13 & 0.11 \\
\hline 22 & satisfaction & 12 & 0.12 \\
\hline 23 & student & 11 & 0.28 \\
\hline 24 & antecedent & 10 & 0.11 \\
\hline 25 & knowledge sharing & 10 & 0.03 \\
\hline 26 & social network & 10 & 0.05 \\
\hline 27 & web 20 & 9 & 0.09 \\
\hline 28 & academic library & 9 & 0.17 \\
\hline 29 & higher education & 9 & 0.01 \\
\hline 30 & management & 9 & 0.1 \\
\hline
\end{tabular}

From Table 3, it can be observed that the research scope of the VACs is comprehensive. The frequency of social media and the internet appeared 46 and 32 times, respectively, which is the most critical keyword studied by scholars in research community. The keyword such as model, Facebook, participation, trust, communication, technology, and knowledge are researched many times. The keywords such as student $(0.28)$, knowledge $(0.25)$, participation (0.22), and Facebook (0.22) have high centrality, which indicates that the nodes corresponding to these keywords are in a relatively leading position in the given map. The research focus of the VACs can be seen from Figure 2 and Table 2, which contains seven topics: knowledge sharing, literature review, learning analytics, Facebook, interaction effects, web 2.0 and information services.

\subsection{Document co-citation analysis}

The concept of document co-citation was proposed in 1973 by Marshakova and Henry, which refers to the co-citation relationship formed by the simultaneous citation of two or more documents by the third article [9]. Document co-citation analysis (DCA) can be used to identify key literature and research frontiers in a research field. The "cited Reference"'" was used as the node in the citespace, set $\mathrm{LBY}=-1$ (no limitation of retroactivity), timeslice $=3$ years, and top $\mathrm{N}=30$. The document co-citation map of the VACs was obtained by using Pathfinder pruning and displaying in a time-zone mode, which is shown in figure 2 . According to Figure 2, it can be seen that the co-citation relationship in the field of VACs in 1995-2020 is very close, while the high citation contribution is more concentrated in the period 2004-2010. Of these, there were Fishbein and Ajzen, Davis and Bagozzi two high cited documents before 1995, which were cited 20 times [10-11]; between 1995 and 2003, there were five high cited documents, mainly Nahapiet, Preece, which were cited 67 times [12-14]; during 2004-2010, there were six high cited documents, such as Chiu et al, Hsu et al, Wasko and Faraj, which were cited 100 times [15-17]. After 2010, the number of references to relevant research literature in VACs was relatively low. In order to better study the theoretical results in this field, the first five cited literatures in this field are listed, which is shown in Table 4 below.

\subsection{Frontier and Trend Analysis}

The Burst Detection Algorithm was proposed by Kleinberg in 2002, He believes the term high burst has an intelligence function, and can reflect the frontier of research field [18]. According to the literature retrieved by WOS, we click Burstness 
button and set the Minimum duration to 1 year for Burst Detection. The first 11 mutation keywords were obtained, and they reveal different stages and future trends in VACs. Keywords in the graph represent the corresponding keywords, year indicates the first time in the retrieval record, strength indicates the strength of the mutation, beginning indicates when the mutation started, ending means the end time. The start and end time of the year corresponds to a small red rectangular block.

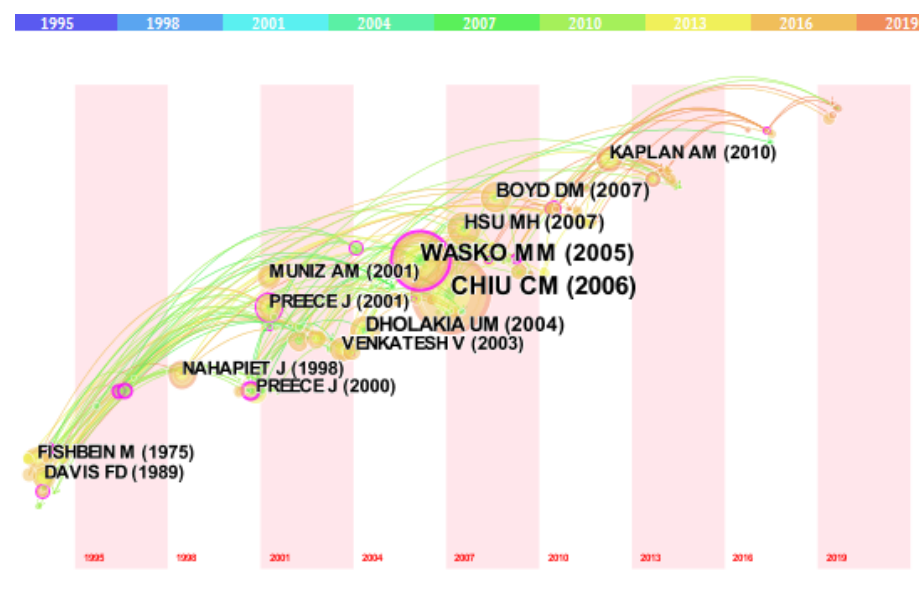

Figure 2: Map of Document Co-citation Time Zones

Table 4:. High frequency citations literature

\begin{tabular}{|c|c|c|c|c|}
\hline $\mathrm{S} / \mathrm{N}$ & Title of the literature & $\begin{array}{l}\text { Main } \\
\text { Authors }\end{array}$ & $\begin{array}{l}\text { Name of } \\
\text { Journal }\end{array}$ & $\begin{array}{l}\text { Frequency } \\
\text { of citations }\end{array}$ \\
\hline 1 & $\begin{array}{l}\text { Understanding } \\
\text { knowledge sharing in } \\
\text { virtual communities: } \\
\text { An integration of social } \\
\text { capital and social } \\
\text { cognitive theories }\end{array}$ & Chiu C M & $\begin{array}{l}\text { Decision } \\
\text { Support } \\
\text { Systems }\end{array}$ & 33 \\
\hline 2 & $\begin{array}{l}\text { Why Should I Share? } \\
\text { Examining Social } \\
\text { Capital and Knowledge } \\
\text { Contribution in } \\
\text { Electronic Networks of } \\
\text { Practice }\end{array}$ & $\begin{array}{l}\text { Wasko } \mathrm{M} \\
\mathrm{M}\end{array}$ & $\begin{array}{l}\text { MIS } \\
\text { Quarterly }\end{array}$ & 24 \\
\hline 3 & $\begin{array}{lr}\text { Knowledge } & \text { sharing } \\
\text { behavior in virtual } \\
\text { communities: } \\
\text { relationship } \text { The } \\
\text { trust, self-efficacy, and } \\
\text { outcome expectations }\end{array}$ & Hsu M H & $\begin{array}{l}\text { Internatio } \\
\text { nal Journal } \\
\text { of Human- } \\
\text { Computer } \\
\text { Studies }\end{array}$ & 15 \\
\hline 4 & $\begin{array}{l}\text { Social Network Sites: } \\
\text { Definition, History, } \\
\text { and Scholarship }\end{array}$ & Boyd D M & $\begin{array}{l}\text { Journal of } \\
\text { Computer- } \\
\text { Mediated } \\
\text { Communi } \\
\text { cation }\end{array}$ & 14 \\
\hline 5 & $\begin{array}{lr}\text { A social influence } \\
\text { model of consumer } \\
\text { participation } \\
\text { network- and } \\
\text { group-based } \\
\text { communities }\end{array}$ & $\begin{array}{l}\text { Dholakia } \\
\text { U M }\end{array}$ & $\begin{array}{l}\text { Internatio } \\
\text { nal Journal } \\
\text { of } \\
\text { Research } \\
\text { in } \\
\text { Marketing }\end{array}$ & 13 \\
\hline
\end{tabular}

www.astesi.com

\section{Top 11 Keywords with the Strongest Citation Bursts}

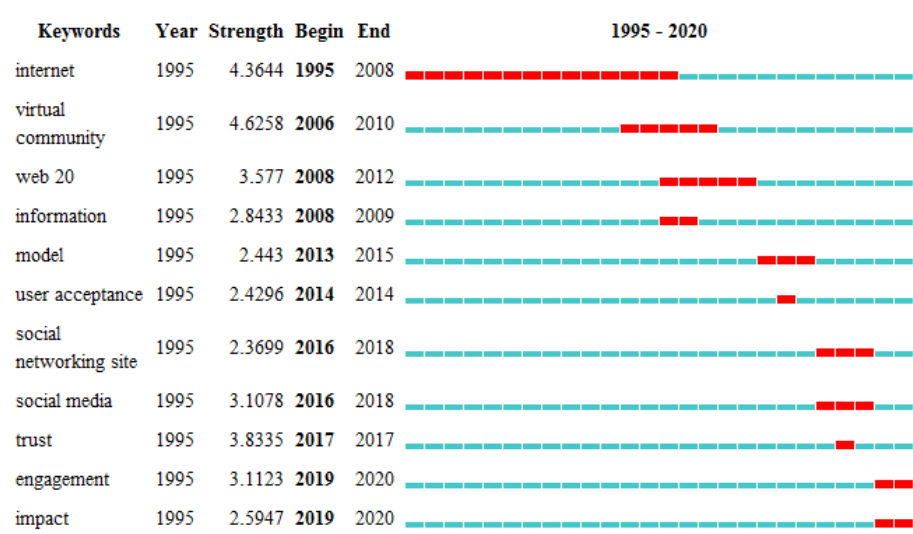

Figure 3: Burst Detection of Keywords

Figure 3 shows that during the period 1995-2020, virtual community and internet had the strongest burst intensities, and were respectively concentrated in the period 1995-2008 and 20062010. Model, user acceptance, social networking site, social medica, and trust have a certain degree of burst After 2010, which illustrates the research hotspots and frontiers in this stage focused on social networking sites, acceptance, models in the VACS. while Engagement (participation) and impact burst intensities were 3.1123 and 2.5947 respectively from 2019 to 2020 .

\subsection{Disciplinary Overlay Analysis}

Disciplinary overlay analysis can use the coupling relation of the literature to analyze the internal relation between the discipline involved in the literature [19]. Figure 4 is obtained by using the Zscorce algorithm to superposition and simplify the literature data of the VACs, in which the thickness of the lines indicates the degree of connection between the disciplines. The Part1 area in the figure is constructed by the discipline relationship of the citing literature, and the Part2 area is constructed by the discipline relationship of the cited literature.

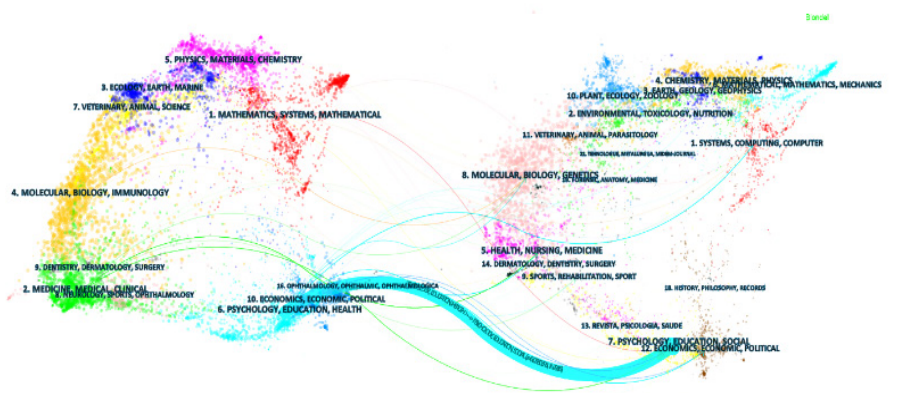

Figure 4: Disciplinary Overlay Map of VACs

Figure 4 shows that the research on VACs in the Partl focuses on psychology, education, health, and economics, and these disciplines provide a developing knowledge base for research of VACs. Part2 shows that the research literature of VACs has been cited in psychology, education, society, environmental science and 
biomolecules. Research in economics, which is less distributed, is more often cited in computer science.

\section{Findings and Discussion}

\subsection{Findings}

This paper uses the bibliometric method, with the help of bibliometric analysis software Citespace and VOSviewer, to analyze the annual publish amount, key authors, keywords and citations of the literature, and uses the Document Xo-citation Analysis, the Keywords Clustering Algorithm, the Burst detection algorithm and the Z-scorce algorithm to analyze the research hot spots, research frontiers and evolution trends in the field of VACs to provide key knowledge reference for related researchers.

According to the statistics of the trend of the number of papers, the development of the research field of virtual academic community has experienced three stages. They are initial development (1995-2007), climbing period (2008-2014), and rapid development period (2015-2020). The document co - cited analysis shows that, Fishbein、Davis、Nahapiet、Preece、Wasko 、 Chiu 、 Hsu are the high frequency cited authors of the VACs fields. "Understanding knowledge sharing in virtual communities : An integration of social capital and social cognitive theories", "Act Why Should I Share? Act Examining Social Capital and Knowledge Contribution in Electronic Networks of Practice", and "Knowledge sharing behavior in virtual communities: The relationship between trust, self-efficacy, and outcome expectations" are the high frequency cited articles of VACs fields. Based on co-citation statistics and knowledge maps, researchers can quickly master the important knowledge in this field.

Research hotspots and cutting-edge surveys show that the research results, the research contents of virtual academic community mainly include knowledge sharing, literature review, learning analytics, Facebook, interaction effects, web 2.0 and information services and so on. Burst detection results show that Model, user acceptance, social networking site, social medica, trust, engagement, and impact is the latest frontier topic in this field. The key nodes of central screening show the evolution path of domain development, and further reveal the trend of domain development, which provides researchers with panoramic view of VACs.

\subsection{Discussion}

The following is a discussion of research topics in the field of VACs and the views of major scholars. Keywords Clustering map in figure 1 show that the research subjects of VACs mainly focus as follow.

- knowledge sharing and exchange in VACS and their influencing factors. It can be concluded by analyzing related literatures that many factors influence the behavior of knowledge sharing and exchange in the VACs. From the individual members of the community, psychological state, self-efficacy, social status and the degree of trust between each other are the main influencing factors; from the social environment, the influence of internet technology and cultural factors is more significant; from the community itself, the influence of connectivity and learning perception are more significant.

- The practice and influence of social media in academia. Some researchers conduct a comprehensive literature review of academic social media for the first time, which help to understand better the influencing factors of using social media [20]. Many scholars put forward the views related to academic social media, summarized as follows: Social media can be used as a new way to evaluate academic work, which is considerable to significance the academic researchers and stakeholder [21]. Social media plays a vital role in promoting collaboration and networking in global virtual communities [22]. Social networks are increasingly influential in teenagers [23]. The most comprehensive research review of social media scholarship shows that Facebook has a massive advantage in social networking academic research and more scholars should conduct academic research on social media [24]. The study of teachers using social networks in 22 medical colleges found a total of 40 social media tools, of which the most popular platforms are considered as Facebook by 9 institutions, Twitter by 8 institutions, and blogs by 8 institutions. In conclusion, the trend of social media use in academia is gradually increasing, especially among the young student groups, but there are still a series of problems such as private security, mental health issues are increasing day by day [25].

- The Theoretical Model basis of VACs. On the basis of social capital theory, social cognition theory, social network theory, collective action theory, planning behavior theory and technology acceptance model, researchers have gradually perfected the theoretical framework of VACs. Some scholars use the theory of social capital to construct the influencing factor model of virtual community knowledge sharing with the variables of interaction relationship, trust, reciprocity norm, identity, shared vision and shared language. This literature has the highest citation frequency in the statistical backtracking period, which provides a reference for many researchers [15]. Another study shows how individual motivation and social capital influence knowledge contribution behavior based on the theory of collective action in electronic networks, which argues that personal reputation, experience, and sense of belonging have a positive impact on knowledge sharing, and this literature has also received extensive attention from researchers [16]. A model based on the theory of social cognition shows the relationship between trust, self-efficacy and expectation of results, and considers environmental factors as future research directions [17]. The social impact model of VACs points out that group norms and social identity are two key factors of community participation [26]. The technology acceptance and community factors affect the behavior of participating in virtual communities of 
practice, and the participants' domain knowledge has the most significant influence on the quality of their collaborative results [27]. "Quality of online discussion" is a measure to evaluate the results of virtual community interaction, which is influenced by network interaction, social identity, and social connectivity [28].

\section{Conclusions and limitations}

Combine the keyword burst detection result and the analysis of important literature, we can conclude that participation and social impact research is an important frontier trend in VACs. In addition, the participation behavior and social impact of VACs in different disciplines are different, and quantitative comparative research can be done in the future to provide reference for the overall development of VACs.

The way of knowledge exchange has changed in the era of great science, and the emergence of VACs provides a new platform for knowledge sharing and research cooperation. The existing research on VACs has obtained rich results, and generates a number of representative key researchers and theoretical literature. But the analysis of the evolution and trend of the field shows that the scope of research in this field needs to be expanded, and there are still many controversies about the theoretical model, concept, and structural dimension, which are the directions that researchers need to further study. The research of VACs is a multidisciplinary field, which involves behavioral science, psychology, education, economics information science and so on. Researchers can further expand the field of interdisciplinary research, and enrich the research in this field with the help of the research methods, research perspectives and research paths of different disciplines.

Bibliometrics is a scientific and effective research method of statistics, description and prediction of academic status and development trend. Its analysis of the research field relies on the quantity and quality of the downloaded literature. Based on the database of the core collections included in the WOS, the research results have strong objective impartiality. However, due to the limitations of the database, and some databases do not support the download, so the results may be biased. Future research can consider using data mining technology to expand the scope of source data collection and improve the quantity and quality of literatures.

\section{Conflict of Interest}

The authors declare no conflict of interest.

\section{Acknowledgment}

This study was substantially supported by a project (70901080) from the National Natural Science Foundation of China. The research was substantially supported by a project (19SKGH091) from the Chongqing Education Commission of China and project from the Open Fund of Research Centre of Enterprise Management. This study was also substantially supported by a project (2053002) from Chongqing Technology and Business University of China.

\section{References}

[1] Statista. "Number of social network users world- wide from 2010 to 2021 ( in billions" [EB / OL]. https://www.statista.com/topics/1164/social-networks/. [2018-12-05].

[2] F. Berdun, M. G. Armentano, "Modeling users collaborative behavior with a serious game" IEEE Transactions on Games, 11(2), 121-128, 2018. https://doi.org/10.1109/tg.2018.2794419

[3] H. F. Lin, "Effects of extrinsic and intrinsic motivation on employee knowledge sharing intentions" Journal of Information Science, 33(2), 135149, 2007. https://doi.org/10.1177/0165551506068174

[4] R. F. Ma, X. J. Liang, Y. P. Jiang, "Evolution of academic groups and hotpots of the western cultural and creative industry research institute" World Regional Studies, 24(2), 96-104, 2015. DOI: 10.3969/j.issn.10049479.2015.02.011

[5] N. J. V. Eck, L. Waltman, "Software survey: VOSviewer, a computer program for bibliometric mapping" Scientometrics, 84(2), 523, 2010. https://doi.org/10.1007/s11192-009-0146-3

[6] C. Chen, "Cite Space II: detecting and visualizing emerging trends and transient patterns in scientific literature" Journal of the American Society for Information Science and Technology, 57(3), 359-377, 2006. https://doi.org/10.1002/asi.20317

[7] Y. Chen, Z. Y. Liu, "Quietly rising scientific knowledge graph" Studies in Science of Science, (23)2, 149-154, 2005. DOI: 10.16192/j.cnki.10032053.2005.02.002

[8] J. F. Zhao, F. Jiang, "Study on bibliometrics and scientific knowledge graph in modern college education" University Education Science, 111(1), 115-123, 2014. DOI: 10.3969/j.issn.1672-0717.2014.01.018

[9] H. Small, "Co-citation in scientific literature: a new measure of the relationship between publications" Journal of the America Society of Information Science, 24(4), 265-269, 1973. https://doi.org/10.1002/asi. 4630240406

[10] R. J. Hill, M. Fishbein, I. Ajzen, "Belief, attitude, intention and behavior: An introduction to theory and research" Contemporary Sociology, 6(2), 244, 1977. https://doi.org/10.2307/2065853

[11] F. D. Davis, R. P. Bagozzi, P. R. Warshaw, "User acceptance of computer technology: A comparison of two theoretical models" Management Science 35(8), 982-1003, 1989. https://doi.org/10.1287/mnsc.35.8.982

[12] J. Nahapiet, S. Ghoshal, "Social Capital, Intellectual Capital, and Organizational Advantage" Academy of Management Review, 23(2), 242 266, 1998. https://doi.org/10.1016/b978-0-7506-7222-1.50009-X

[13] J. Preece, "Online communities: Designing usability and supporting Socialbilty" John Wiley \& Sons, Inc., Hoboken. 100(9),459-460, 2000. https://doi.org/10.1108/imds.2000.100.9.459.3

[14] J. Preece, "Sociability and usability in online communities: determining and measuring success" Behavior and Information Technology, 20(5):347-356, 2001. https://doi.org/10.1080/01449290110084683

[15] C. M. Chiu, M. H. Hsu, T. G. Wang, "Understanding knowledge sharing in virtual communities: An integration of social capital and social cognitive theories" Decision Support Systems, 42(3), 1872-1888, 2006. https://doi.org/10.1016/j.dss.2006.04.001

[16] M. M. Wasko, S. Faraj,"Why should I share? Examining social capital and knowledge contribution in electronic networks of practice" MIS Quarterly, 29(3), 35-57, 2005. https://doi.org/10.2307/25148667

[17] M. H. Hsu, T. L. Ju, C.-H. Yen, C. M. Chang, "Knowledge sharing behavior in virtual communities: The relationship between trust, self-efficacy, and outcome expectations" International Journal of Human-Computer Studies, 65(2), 153-169,2007. https://doi.org/10.1016/j.ijhcs.2006.09.003

[18] J. Kleinberg, "Bursty and Hierarchical Structure in Streams". Proceedings of the 8th ACM SIGKDD International Conference on Knowledge Discovery and Dala Mining. Edmonton. Alberta. Canada: ACM Press, 02, 91-101, 2002. https://doi.org/10.1145/775047.775061

[19] C. Chen, "Scarching for intellectual turning points: progressive knowledge domain visualization" Proc Natl Acod Sci USA, 101(1):5303-5310, 2004. https://doi.org/10.1073/pnas.0307513100

[20] E. W. T. Ngai, S. S. C. Tao, K. K. L. Moon, "Social media research: Theories, constructs, and conceptual frameworks" International Journal of Information Management, 35(1), 33-44, 2015. https://doi.org/10.1016/j.ijinfomgt. 2014.09.004

[21] C. Lamberton, A. T. Stephen, "A thematic exploration of digital, social media, and mobile marketing: Research evolution from 2000 to 2015 and an agenda for future inquiry" Journal of Marketing, 80(6), 146-172, 2016. https://doi.org/10.1509/jm.15.0415

[22] I. Hussain, "A study to evaluate the social media trends among university students" Procedia - Social and Behavioral Sciences, 64(9):639-645, 2012. https://doi.org/10.1016/j.sbspro.2012.11.075

[23] J. Ahn, "The effect of social network sites on adolescents social and academic development: Current theories and controversies" Journal of the American 
Society for Information Science and technology, 62(8), 1435-1445, 2011. https://doi.org/10.1002/asi.21540

[24] E. Stoycheff, J. Liu, K. A. Wibowo, D. P. Nanni, "What have we learned about social media by studying Facebook? A decade in review" New Media \& Society, 19(6), 968-980, 2017. https://doi.org/10.1177/1461444817695745

[25] P. S. Cahn, E. J. Benjamin, C. W. Shanahan, “'Uncrunching' time: medical schools' use of social media for faculty development" Medical Education Online, 18(1), 20995, 2013. https://doi.org/10.3402/meo.v18i0.20995

[26] U. M. Dholakia, R. P. Bagozzi, L. K. Pearo, "A social influence model of consumer participation in network- and small-group-based virtual communities" International Journal of Research in Marketing, 21(3), 241263,2004. https://doi.org/10.1016/j.ijresmar.2003.12.004

[27] N. Nistor, B. Baltes, M. Dascălu, D. Mihăilă, G. Smeaton, Ş. Trăuşan-Matu, "Participation in virtual academic communities of practice under the influence of technology acceptance and community factors. A learning analytics application" Computers in Human Behavior, 34, 339-344, 2014. https://doi.org/10.1016/j.chb.2013.10.051

[28] H. P. Shih, E. Huang, "Influences of web interactivity and social identity and bonds on the quality of online discussion in a virtual community" Information Systems Frontiers, 16(4), 627-641,2014. https://doi.org/10.1007/s10796-0129376-7 